\title{
HUBUNGAN DUKUNGAN KELUARGA DAN SOSIAL EKONOMI DENGAN PEMILIHAN TEMPAT PERSALINAN DI PUSKESMAS TEBING TINGGI
}

\author{
Sari, Ruri Maiseptya ${ }^{1 *}$, Sanisahhuri $^{2}$, Martini $^{3}$ \\ 1,2,3 Program Studi D.IV Kebidanan STIKES Tri Mandiri Sakti Bengkulu \\ *Korespondensi: Rury_maiseptyasari@yahoo.com
}

\begin{abstract}
Background: One of the factors of the high MMR in Indonesia is due to the relatively low coverage of help by health workers. Puprose: The purpose of this study was to determine the relationship of family and socioeconomic support with the choice of delivery place in Puskesmas Tebing Tinggi. Methods: This study is analytic survey with cross sectional design. The research population in this study was trimester III pregnant women in Puskesmas Tebing Tinggi in July 2019, amounting to 52 people. The sample in this study was third trimester pregnant women who are in Tebing Tinggi Health Center taken in total sampling. Data collection is done using primary data. Results: The results of the study of 52 pregnant women respondents who chose non-health service facilities were 31 respondents and those who chose health service facilities were 21 respondents. From 52 family respondents who support as many as 30 respondents and do not support as many as 22 respondents, from 52 respondents with socioeconomic $<\mathrm{UMR}$ as many as 35 respondents and $\geq \mathrm{UMR}$ as many as 17 respondents. Chisquare test results obtained value $\chi 2=4.278$ with $p$ value $=0.05$ meaning that there is a relationship of family support with the choice of delivery place in Tebing Tinggi Health Center with a moderate category. Chi-square test results (Pearson chisquare) obtained value $\chi^{2}=8.27$ with $\mathrm{p}$ value $=0.05$ means that there is family support by choosing the place of delivery at Tebing Tinggi Health Center with a moderate category. Conclusion: It was concluded that there was a significant relationship between family support and socio-economics with the choice of delivery place in the Tebing Tinggi Health Center with a moderate category.
\end{abstract}

Keywords: Family Support; Economic Sociology; Selection of Childbirth

\begin{abstract}
ABSTRAK
Latar Belakang: Salah satu faktor tingginya AKI di Indonesia adalah karena relatif masih rendahnya cakupan pertolongan oleh tenaga kesehatan Tujuan: Tujuan penelitian ini adalah untuk mengetahui hubungan dukungan keluarga dan sosial ekonomi dengan pemilihan tempat persalinan di Puskesmas Tebing Tinggi. Metode: Penelitian ini menggunakan Survei Analitik dengan Pendekatan Cross Sectional Populasi penelitian dalam penelitian ini ibu hamil trimester III di Puskesmas Tebing Tinggi bulan Juli 2019 yang berjumlah 52 orang. Sampel pada
\end{abstract}


penelitian ini adalah ibu hamil trimester III yang berada di Puskesmas Tebing Tinggi yang diambil secara total sampling. Pengumpulan data dilakukan menggunakan data primer. Hasil: Hasil penelitian dari 52 responden ibu hamil yang memilih non fasilitas pelayanan kesehatan sebanyak 31 responden dan yang memilih fasilitas pelayanan kesehatan 21 responden. Dari 52 responden keluarga yang mendukung sebanyak 30 responden dan tidak mendukung sebanyak 22 responden, Dari 52 responden dengan sosial ekonomi <UMR sebanyak 35 responden dan $\geq$ UMR sebanyak 17 responden. Hasil uji Chi-square didapat nilai $\chi^{2}=4,278$ dengan $\mathrm{p}$ value $=0,05$ artinya ada hubungan dukungan keluarga dengan pemilihan tempat persalinan di Puskesmas Tebing Tinggi dengan kategori sedang. Hasil uji Chi-square (pearson chi-square) didapat nilai $\chi^{2}=8,27$ dengan $p$ value $=0,05$ artinya ada dukungan keluarga dengan pemilihan tempat persalinan di Puskesmas Tebing Tinggi dengan kategori sedang. Simpulan: Disimpulkan bahwa Ada hubungan yang signifikan antara dukungan keluarga dan Sosial Ekonomi dengan pemilihan tempat persalinan di Puskesmas Tebing Tinggi dengan kategori sedang.

Kata Kunci : Dukungan Keluarga, Sosial Ekonomi, Pemilihan Tempat Persalinan

\section{PENDAHULUAN}

Sustainble Development Goals mempunyai tujuan meningkatkan kesehatan ibu dan anak. Indiktor kesehatan ibu dan anak serta masyarakat yaitu menurunkan angka kesakitan dan kematian ibu dan bayi. Banyaknya kematian ibu pada masa kehamilan, persalinan dan nifas merupakan angka kematian ibu (AKI) (Hidayati, 2018).

World Health Organization (WHO) tahun 2015, melaporkan AKI didunia sebesar 216/100.000 kelahiran hidup. AKI di Indonesia sebesar 126/100.000 kelahiran hidup dan angka ini masih sangat jauh dari target Sustainable Development Goals (SDG's) untuk menurunkan AKI menjadi 70/100.000 kelahiran hidup (BAPPENAS, 2017).

Salah satu faktor tingginya AKI di Indonesia adalah karena relatif masih rendahnya cakupan pertolongan oleh tenaga kesehatan. Rendahnya pendidikan di masyarakat, budaya dan ekonomi menjadikan sebagian masyarakat memilih bersalin pada tenaga non kesehatan (dukun) (Nurhidayanti, Margawati, \& Kartasurya, 2018).

Di Indonesia pada tahun 2016 persalinan dengan ditolong oleh tenaga kesehatan dan dilakukan difasilitas pelayanan kesehatan sebesar 80,61\%. Secara 
nasional indikator tersebut telah memenuhi target Renstra sebesar 77\% (Kemenkes RI, 2017). Pada tahun 2017 persalinan dengan ditolong oleh tenaga kesehatan dan dilakukan difasilitas pelayanan kesehatan sebesar 83,67\%. Secara nasional, indikator tersebut telah memenuhi target Renstra yang sebesar 79\% (Kemenkes RI, 2018).

Data Dinas Kesehatan Provinsi Sumatera Selatan tahun 2016 persalinan dengan ditolong oleh tenaga kesehatan dan dilakukan difasilitas pelayanan kesehatan sebesar $81,6 \%$. Secara nasional indikator tersebut telah memenuhi target Renstra sebesar 77\% (Dinas Kesehatan Provinsi Sumatera Selatan, 2017). Pada tahun 2017 persalinan dengan ditolong oleh tenaga kesehatan dan dilakukan difasilitas pelayanan kesehatan sebesar $83,91 \%$. Secara nasional, indikator tersebut telah memenuhi target Renstra yang sebesar 79\% (Dinas Kesehatan Provinsi Sumatera Selatan, 2018).

Dukungan keluarga dan social ekonomi menjadi faktor yang berhubungan dengan pemilihan tempat persalinan. Orang yang merasa memperoleh dukungan sosial, secara emosional merasa lega diperhatikan, mendapat saran atau kesan yang menyenangkan pada dirinya. Pada hakekatnya keluarga diharapkan mampu berfungsi untuk mewujudkan proses pengembangan timbal balik rasa cinta dan kasih sayang antara anggota keluarga, antar kerabat, serta antar generasi yang merupakan dasar keluarga yang harmonis (Nurjanah \& Marliyah, 2016). Menurut Penelitian Prihatin dkk (2017), bahwa ada hubungan antara dukungan keluarga dengan pemilihan tempat persalinan (Prihatin \& Winarni, 2017).

Pendapatan keluarga merupakan salah satu faktor determinan terhadap akses menuju pelayanan kesehatan.Hal ini menjadi alasan perempuan untuk lebih memilih rumah sebagai tempat persalinan karena mereka beralasan bahwa pemilihan persalinan di rumah lebih sedikit membutuhkan biaya dibandingkan persalinan di fasilitas kesehatan. Mereka menganggap dengan bersalin di rumah bisa menghemat pengeluaran untuk biaya persalinan dan uang persalinan dapat dialihkan untuk membayar jasa tenaga kesehatan(Putri, 2016). Penelitian Prihatin dkk (2017), menyatakan hubungan antara karakteristik tingkat ekonomi terhadap pemilihan tempat bersalin pada penelitian ini. 
Data Dinas Kesehatan Provinsi Sumatera Selatan tahun 2016 didapatkan Kabupaten dengan persentase tertinggi persalinan dengan ditolong oleh tenaga kesehatan dan dilakukan difasilitas pelayanan kesehatan yaitu Kota Palembang (100\%), Kabupaten Muratara (99,46\%) dan Kabupaten Oku Selatan (97,98\%). Selanjutnya, persentase terendah persalinan dengan ditolong oleh tenaga kesehatan dan dilakukan difasilitas pelayanan kesehatan yaitu Empat Lawang (74,01\%), Kabupaten Musi Rawas (84,85\%) dan Kabupaten Organ Komering Ulu (89,12\%) (Dinas Kesehatan Provinsi Sumatera Selatan, 2017)

Data Dinas Kesehatan Provinsi Sumatera Selatan tahun 2017 didapatkan Kabupaten dengan persentase tertinggi persalinan dengan ditolong oleh tenaga kesehatan dan dilakukan difasilitas pelayanan kesehatan yaitu Kota Palembang (99,21\%), Kabupaten PALI (99,37\%) dan Kabupaten Ogan Ilir (97,27\%). Selanjutnya, persentase terendah persalinan dengan ditolong oleh tenaga kesehatan dan dilakukan difasilitas pelayanan kesehatan yaitu Empat Lawang (75,82\%), Kabupaten Musi Banyuasin (83,16\%) dan Kabupaten Muratara (87,63\%) (Dinas Kesehatan Provinsi Sumatera Selatan, 2018).

Data diatas menunjukkan bahwa Kabupaten Empat Lawang menjadi Kabupaten dengan persentase tertinggi persalinan yang dilakukan di non fasilitas kesehatan. Data Dinas Kesehata Kabupaten Empat Lawang tahun 2016 didapatkan Puskesmas dengan angka tertinggi persalinan yang dilakukan di non fasilitas pelayanan kesehatan adalah Puskesmas Tebing Tinggi (380), Puskesmas Lesung Batu (366) dan Puskesmas Muara Pinang (312) (Dinas Kesehatan Kabupaten Empat Lawang, 2017).

Data Dinas Kesehata Kabupaten Empat Lawang tahun 2017 didapatkan Puskesmas dengan angka tertinggi persalinan yang dilakukan di non fasilitas pelayanan kesehatan adalah Puskesmas Tebing Tinggi (328), Puskesmas Lesung Batu (309) dan Puskesmas Sikap Dalam (240) (Dinas Kesehatan Kabupaten Empat Lawang, 2018).

Data Dinas Kesehata Kabupaten Empat Lawang tahun 2018 didapatkan Puskesmas dengan angka tertinggi persalinan yang dilakukan di non fasilitas pelayanan kesehatan adalah Puskesmas Tebing Tinggi (250), Puskesmas Sikap 
Dalam (159) dan Puskesmas Talang Padang (121) (Dinas Kesehatan Kabupaten Empat Lawang, 2019).

Survei awal yang dilakukan di Puskesmas Tebing Tinggi Kabupaten Empat Lawang pada tanggal 10 Juni 2019 dari 5 persalinan didapatkan bahwa 3 diantaranya dilakukan di rumah dan 2 di Puskesmas. 3 ibu yang bersalin di rumah dikarenakan adanya dukungan keluarga supaya bisa melihat persalinan Selanjutnya, 2 orang yang bersalin dengan Bidan karena mempunyai biaya yang cukup bersalin dengan Bidan dan mendapat dukungan penuh dari keluarga karena anak sebelumnya juga melahirkan dengan Bidan.

Rumusan masalah dalam penelitian ini, apakah ada hubungan dukungan keluarga dan sosial ekonomi dengan pemilihan tempat persalinan di Puskesmas Tebing Tinggi?.

Tujuan Penelitan ini secara umum Untuk Mengetahui hubungan dukungan keluarga dan sosial ekonomi dengan pemilihan tempat persalinan di Puskesmas Tebing Tinggi dan tujuan secara khususnya untuk mengetahui distribusi frekuensinya dan hubungan antara dukungan keluarga dengan pemilihan tempat persalinan di Puskesmas Tebing Tinggi dan hubungan sosial ekonomi dengan pemilihan tempat persalinan di Puskesmas Tebing Tinggi.

\section{METODE}

Rancangan yang digunakan dalam penelitian survei analitik dengan pendekatan Cross Sectional di Puskesmas Tebing Tinggi Kabupaten Empat Lawang pada 9 Juli 2019 sampai 9 Agustus tahun 2019. Populasi dalam penelitian ini adalah ibu hamil trimester III di Puskesmas Tebing Tinggi bulan Juli 2019 yang berjumlah 52 orang diambil secara total sampling. Pengumpulan data mengunakan data primer merupakan data yang langsung diambil dengan berhadapan bersama responden. Data primer dalam penelitian ini menggunakan kuesioner yang terdiri dari identitas responden meliputi nama, usia, jumlah anak, pendidikan, pekerjaan. Kuesioner meliputi dukungan keluarga dan data sekunder melihat buku register puskesmas. Teknik analisis data dengan univariat bertujan 
untuk mengetahui karakristik sampel dan bivariat untuk mentukan hubungan antara variabel, menggunakan uji Chi Square $\left(X^{2}\right)$ dan Coefficient Contingency (C).

\section{HASIL}

\section{Analisa Univariat}

Analisis ini dilakukan untuk melihat distribusi frekuensi pemilihan tempat persalinan, dukungan keluarga dan sosial ekonomi

Tabel 1 Distribusi Frekuensi Pemilihan Tempat Persalinan, Dukungan Keluarga dan Sosial Ekoomi di Puskesmas Tebing Tinggi

\begin{tabular}{lcc}
\hline \multicolumn{1}{c}{ Karakteristik } & Jumlah (n) & Persentase (\%) \\
\hline Pemilihan tempat pesalinan & & \\
Non fasilitas pelayanan kesehatan & 31 & 59,6 \\
Fasilitas pelayanan kesehatan & 21 & 40,4 \\
Dukungan Keluarga & & \\
Tidak Mendukung & 30 & 57,7 \\
Mendukung & 22 & 42,3 \\
Sosial EKonomi & & \\
<UMR & 35 & 67,3 \\
$\geq$ UMR & 17 & 32,7 \\
\hline
\end{tabular}

Dari tabel 1 didapatkan ibu hamil yang memilih non fasilitas pelayanan kesehatan sebanyak 31 responden dan yang memilih fasilitas pelayanan kesehatan 21 responden dan keluarga yang mendukung sebanyak 22 responden dan tidak mendukung sebanyak 30 responden. Sedangkan responden dengan sosial ekonomi $<$ UMR sebanyak 35 responden dan $\geq$ UMR 17 responden.

\section{Analisa Bivariat}

Analisis ini dilakukan untuk mengetahui hubungan dukungan keluarga dan sosial ekonomi dengan pemilihan tempat persalinan di Puskesmas Tebing Tinggi.

Tabel 2 Hubungan Dukungan Keluarga dengan Pemilihan Tempat Persalinan di Puskesmas Tebing Tinggi

\begin{tabular}{|c|c|c|c|c|c|c|c|}
\hline \multirow{3}{*}{ No } & \multirow{3}{*}{$\begin{array}{c}\text { Dukungan } \\
\text { keluarga }\end{array}$} & \multicolumn{2}{|c|}{$\begin{array}{c}\text { Pemilihan Tempat } \\
\text { Persalinan }\end{array}$} & \multirow[b]{2}{*}{ Total } & \multirow{3}{*}{$\chi^{2}$} & \multirow{3}{*}{$p$} & \multirow{3}{*}{$C$} \\
\hline & & $\begin{array}{c}\text { Non } \\
\text { fasilitas } \\
\text { pelayanan } \\
\text { kesehatan }\end{array}$ & $\begin{array}{c}\text { Fasilitas } \\
\text { pelayanan } \\
\text { kesehatan }\end{array}$ & & & & \\
\hline & & F $\%$ & $\%$ & $\mathbf{F}$ & & & \\
\hline
\end{tabular}




\begin{tabular}{|c|c|c|c|c|c|c|c|c|c|}
\hline 1. & $\begin{array}{l}\text { Tidak } \\
\text { mendukung }\end{array}$ & 22 & 73,3 & 8 & 26,7 & 30 & 100 & \multirow{3}{*}{$4,278 \quad 0,039$} & \multirow{3}{*}{0,310} \\
\hline 2. & Mendukung & 9 & 40,9 & 13 & 59,1 & 22 & 100 & & \\
\hline & Total & 31 & 57,1 & 21 & 42,9 & 52 & 100 & & \\
\hline
\end{tabular}

Dari tabel 2 didapatkan dukungan keluarga dengan pemilihan tempat persalinan di Puskesmas Tebing Tinggi didapatkan bahwa dari 30 keluarga yang tidak mendukung sebanyak 22 orang memilih tempat bersalin di non fasilitas pelayanan kesehatan dan 8 orang fasilitas pelayanan kesehatan. Kemudian, dari 22 keluarga mendukung sebanyak 13 orang memilih fasilitas pelayanan kesehatan dan 9 orang memilih non fasilitas pelayanan kesehatan.

Hasil uji Chi-square (continuity correction) didapat nilai $\chi^{2}=4,278$ dengan $\operatorname{asymp} . \operatorname{sig}(\mathrm{p})=0,039<0,05$ berarti signifikan maka Ho ditolak dan Ha diterima. Jadi ada hubungan dukungan keluarga

Tabel 3 Hubungan Sosial Ekonomi dengan Pemilihan Tempat Persalinan di Puskesmas Tebing Tinggi

\begin{tabular}{|c|c|c|c|c|c|c|c|c|c|c|}
\hline \multirow[t]{3}{*}{ No } & \multirow{3}{*}{$\begin{array}{l}\text { Sosial } \\
\text { Ekonomi }\end{array}$} & \multicolumn{4}{|c|}{$\begin{array}{c}\text { Pemilihan Tempat } \\
\text { Persalinan }\end{array}$} & \multirow{2}{*}{\multicolumn{2}{|c|}{ Total }} & \multirow{3}{*}{$\chi^{2}$} & \multirow{3}{*}{$p$} & \multirow{3}{*}{$C$} \\
\hline & & \multicolumn{2}{|c|}{$\begin{array}{c}\text { Non fasilitas } \\
\text { pelayanan } \\
\text { kesehatan } \\
\end{array}$} & \multicolumn{2}{|c|}{$\begin{array}{l}\text { Fasilitas } \\
\text { pelayanan } \\
\text { kesehatan }\end{array}$} & & & & & \\
\hline & & $\mathrm{F}$ & $\%$ & $\mathrm{~F}$ & $\%$ & $\mathrm{~F}$ & $\%$ & & & \\
\hline 1. & $<\mathrm{UMR}$ & 25 & 71,4 & 10 & 28,6 & 35 & 100 & & & \\
\hline 2. & $\geq \mathrm{UMR}$ & 6 & 35,3 & 11 & 64,7 & 17 & 100 & 4,794 & 0,029 & 0,327 \\
\hline & Total & 31 & 53,35 & 21 & 46,65 & 62 & 100 & & & \\
\hline
\end{tabular}

Dari tabel 3 diperoleh dari 35 orang dengan sosial ekonomi <UMR sebanyak 25 memilih non fasilitas pelayanan kesehatan dan 10 orang memilih fasilitas pelayanan kesehatan. Kemudian, 17 orang yang memiliki sosial ekonomi $\geq$ UMR sebanyak 6 orang memilih non fasilitas pelayanan kesehatan dan 11 orang memlilih fasilitas pelayanan kesehatan.

Hasil uji Chi-square (continuity correction) didapat nilai $\chi^{2}=4,794$ dengan $\operatorname{asymp} \cdot \operatorname{sig}(\mathrm{p})=0,029<0,05$ berarti signifikan maka Ho ditolak dan Ha diterima. Jadi ada hubungan dukungan keluarga dengan pemilihan tempat persalinan di Puskesmas Tebing Tinggi. 


\section{PEMBAHASAN}

Hasil penelitian didapatkan ibu hamil yang memilih non fasilitas pelayanan kesehatan sebanyak 31 responden. 6 orang dikarenakan keluarga tidak memberikan bacaan tentang tempat pemilihan persalinan misal dalam bentuk buku, majalah maupun tabloid, 17 orang karena keluarga tidak mendukung dan sosial ekonomi < UMR dan 7 orang biaya lebih murah serta 1 orang dikarenakan keluarga mendukung melahirkan dengan dukun.

Hasil penelitian ini didukung oleh penelitian Arief (2010), dengan judul Determinan Pemilihan Persalinan Di Fasilitas Kesehatan (Analisis Data Riset Kesehatan Dasar Tahun 2010), yang mengatakan bahwa masih ada ibu yang bertempat tinggal di wilayah perkotaan memilih persalinan di non-fasilitas kesehatan walaupun terdapat kemudahan akses ke fasilitas kesehatan. (Arief \& Sudikno, 2010)

Hasil penelitian didapatkan ibu hamil yang memilih fasilitas pelayanan kesehatan 21 responden. 8 responden memilih fasilitas pelayanan kesehatan karena ada Kartu Indonesia Sehat (KIS), 2 responden karena riwayat perdarahan, serta 11 responden dengan sosial ekonomi >=UMR.

Hasil penelitian ini didukung oleh penelitian Rumengan (2015), dengan judul Faktor-Faktor yang Berhubungan dengan Pemanfaatan Pelayanan Kesehatan Pada Peserta BPJS Kesehatan di Puskesmas Paniki Bawah Kecamatan Mapanget Kota Manado, yang mengatakan bahwa kelompok masyarakat yang tergolong pendapatan relatif kurang memiliki kesulitan untuk mendapatkan pelayanan kesehatan yang baik. Pelaksanaan program layanan kesehatan yang dilakukan BPJS telah banyak membantu kelompok masyarakat dengan pendapatan ekonomi yang kurang untuk mendapatkan layanan kesehatan yang sesuai namun masih banyak responden tidak memanfaatkan Puskesmas (Rumengan \& Kandou, 2015)

Hasil penelitian didapatkan bahwa keluarga yang tidak mendukung sebanyak 30 responden. 22 responden memilih tempat bersalin di fasilitas kesehatan karena mendapatkan dukungan dalam bentuk pujian kepada ibu ketika 
menentukan tempat persalinan. Dukungan ini lebih banyak diberikan responden karena hanya mengucapkan saja kepada istrinya dan 8 responden memilih tempat persalinan di non fasilitas kesehatan.

Hasil Penelitian ini didukung oleh Penelitian Putri (2016), dengan judul Faktor-Faktor yang Berhubungan dengan Pemilihan Tempat Persalinan Tahun 2015 (Studi di Kecamatan Sarolangun Kabupaten Sarolangun Jambi), mengatakan bahwa responden mendapatkan dukungan keluarga tentang keluarga dalam memutuskan masalah penolong persalinan dalam rumah tangga, di musyawarahkan antara ibu dan keluarga. Dukungan keluarga adalah sikap, tindakan, penerimaan keluarga terhadap anggota keluarganya, berupa dukungan informasional, dukungan penilaian, dukungan intrumental dan dukungan emosional. Dukungan keluarga merupakan dukungan dan motivasi yang diberikan anggota keluarga baik pada pemeriksaan kehamilan maupun saat melahirkan (Putri, 2016)

Hasil penelitian didapatkan bahwa keluarga mendukung sebanyak 22 responden. 13 responden memilih pelayanan fasilitas kesehatan karena 5 responden ada Kartu Indonesia Sehat (KIS), 7 responden sosial ekonomi >= UMR, 1 orang memilih fasilitas kesehatan karena ada riwayat perdarahan sebelumnya. Kemudian 9 responden memilih non fasilitas pelayanan kesehatan disebabkan sosial ekonomi $<$ UMR.

Suami dan keluarga memiliki peranan penting dalam memilih penolong selama kehamilan, persalinan dan nifas. Suami dan keluarga yang peduli terhadap kondisi kehamilan dan persalinan wanita akan mendukung dan menyarankan untuk senantiasa memeriksakan dan mempercayakan persalinan kepada yang lebih berkompeten seperti tenaga kesehatan. Karena jika terjadi sesuatu yang buruk, maka seluruh keluarga dan terutama orang tua akan ikut bertanggung jawab (Nurjanah \& Marliyah, 2016)

Hasil penelitian didapatkan responden dengan sosial ekonomi <UMR sebanyak 35 responden. 25 responden memilih non fasilitas pelayanan kesehatan karena sosial ekonomi <UMR dan keluarga tidak mendukung, kemudian 8 responden memilih fasilitas pelayanan kesehatan karena mendapat dukungan dari 
keluarga dan ada Kartu Indonesia Sehat (KIS), kemudian 2 responden karena riwayat perdarahan. Responden dengan sosial ekonomi <UMR akan lebih banyak melakukan persalinan di non fasilitas pelayanan kesehatan karena terkait dengan biaya. Penghasilan keluarga merupakan hal yang penting dalam memenuhi kebutuhan pokok (primer) maupun kebutuhan sekunder, keluarga dengan status ekonomi baik akan lebih mudah tercukupi kebutuhannya dibandingkan keluarga dengan status ekonomi rendah. Persiapan keuangan sangat diperlukan dalam persiapan proses kehamilan, melahirkan maupun masa nifas dan komplikasi yang kemungkinan dapat terjadi.

Hasil penelitian ini di dukung oleh penelitian Putri (2016), dengan judul Faktor-Faktor yang Berhubungan dengan Pemilihan Tempat Persalinan Tahun 2015 (Studi di Kecamatan Sarolangun Kabupaten Sarolangun Jambi), mengatakan bahwa pendapatan keluarga mempengaruhi dalam pemanfaatan pelayanan kesehatan dalam hal ini pemilihan tempat persalinan. Pendapatan keluarga merupakan salah satu faktor determinan terhadap akses menuju pelayanan kesehatan. Pendapatan menjadi alasan perempuan untuk lebih memilih rumah sebagai tempat persalinan, karena mereka beralasan bahwa pemilihan persalinan di rumah lebih sedikit membutuhkan biaya dibandingkan persalinan di fasilitas kesehatan. Mereka menganggap dengan bersalin di rumah bisa menghemat pengeluaran untuk biaya persalinan dan uang persalinan dapat dialihkan untuk membayar jasa tenaga kesehatan (Putri, 2016)

Hasil penelitian didapatkan responden dengan sosial ekonomi $\geq \mathrm{UMR}$ sebanyak 17 responden. 11 responden memilih fasilitas kesehatan dan 6 responden yang memilih non failitas pelayanan kesehatan karena biaya lebih murah.

Pendapatan keluarga mempengaruhi keluarga dalam membayar pelayanan kesehatan yang dibutuhkan seperti pertolongan persalinan, membeli obat, membayar biaya pelayanan, membayar biaya transportasi ke tempat pelayanan kesehatan dan sebagainya. Semakin besar pendapatan dalam keluarga, maka semakin besar peluang ibu dan keluarga untuk memilih fasilitas kesehatan sebagai tempat persalinan (Putri, 2016) 
Hasil Penelitian didapatkan 30 keluarga yang tidak mendukung sebanyak 22 responden yang melakukan persalinan di non fasilitas pelayanan kesehatan karena tidak mendapatkan dukungan baik informasional, instrumental maupun emosional dan 8 responden yang melakukan persalinan di fasilitas pelayanan kesehatan karena 3 responden memiliki Kartu Indonesia Sehat (KIS) 1 orang ada riwayat perdarahan 4 oresponden kelurganya tidak marah dan tidak menyalahkan reponden saat membahas mengenai masalah persalinan dan kadang-kadang mereka memberikan pujian saat responden memutuskan memilih bersalin dengan bidan.

Hasil penelitian ini di dukung oleh penelitian Putri (2016), dengan judul Faktor-Faktor yang Berhubungan dengan Pemilihan Tempat Persalinan Tahun 2015 (Studi di Kecamatan Sarolangun Kabupaten Sarolangun Jambi), mengatakan bahwa dukungan sosial dan materil memberikan pengaruh yang besar dalam menentukan pemilihan penolong dan tempat persalinan. Ibu bersalin yang mendapat dukungan keluarga cenderung memilih tenaga dan fasilitas kesehatan untuk pertolongan persalinan dibandingkan dengan yang tidak mendapat dukungan keluarga. Pemberdayaan dan kemandirian seorang wanita, serta peningkatan pengetahuan seorang ibu bersalin terhadap bahaya dan komplikasi persalinan menjadikan seorang wanita secara mandiri dapat mengambil keputusan yang baik bagi kesehatannya, khususnya dalam pemilihan tempat persalinan (Putri, 2016)

Hasil Penelitian didapatkan 22 keluarga mendukung sebanyak 13 responden memilih fasilitas pelayanan kesehatan karena dan 9 responden memilih non fasilitas pelayanan kesehatan. Faktor lain yang ditemukan 6 responden keluarga tidak memberikan bacaan tentang tempat persalinan misal dalam bentuk buku, majalah dan tabloid kemudian 1 responden kelurganya mendukung melahirkan dengan dukun dan 2 responden kadang-kadang keluarga memberikan pujian kepada responden saat memutuskan tempat persalinan dengan bidan.

Hasil penelitian ini di dukung oleh penelitian Hidra (2017), dengan judul Faktor Yang Berhubungan Dengan Pemilihan Tenaga Penolong Persalinan Di Wilayah Kerja Puskesmas Pasir Putih Kabupaten Muna Tahun 2016, mengatakan bahwa keluarga yang memberikan dukungan, anjuran dan motivasi baik pada saat 
pemeriksaan kehamilan, maupun persalinan. Pengaruh keluarga sangat menentukan ibu yang akan bersalin untuk memilih tempat maupun tenaga penolong persalinan (Hidra, Majid, \& Rasma, 2017)

Hasil penelitian diperoleh dari 35 orang dengan sosial ekonomi <UMR sebanyak 25 memilih non fasilitas pelayanan kesehatan dan 10 responden yang memilih pelayanan kesehatan sebagai tempat persalinan karena 8 responden mempunyai kartu jaminan kesehatan nasional yang berada di Puskesmas Tebing Tinggi sehingga tetap melakukan persalinan di fasilitas pelayanan kesehatan, 2 responden pernah mengalami perdarahan pada kehamilan sebelumnya sehingga bidan menganjurkan ibu untuk melakukan persalinan di fasilitas pelayanan kesehatan.

Hasil penelitian diperoleh dari 17 responden yang memiliki sosial ekonomi $\geq$ UMR sebanyak 11 responden memilih fasilitas pelayanan kesehatan dan 6 responden memilih non fasilitas pelayanan faktor lain karena biaya lebih murah.

Tingkat ekonomi sangat mempengaruhi pemilihan tempat persalinan yang dikarenakan oleh kemampuan biaya masing-masing individu dalam pembiayaan. Semakin tinggi tingkat ekonomi seseorang dalam menentukan tempat persalinan, maka semakin tinggi pula fasilitas kesehatan yang diinginkan. Hal ini berhubungan dengan rasa kenyamanan yang diinginkan, kelengkapan fasilitas, dan biaya yang dapat dijangkau oleh keuangan tiap orang ibu hamil dan pasangan dalam menentukan tempat persalinan nanti (Okang, 2015)

\section{SIMPULAN}

Dari 52 responden terdapat $31(51,6 \%)$ orang yang memilih non fasilitas pelayanan kesehatan Dari 52 responden terdapat $30(57,7 \%)$ orang tidak mendukung. Dari 52 responden terdapat 35 (67,3\%) orang dengan sosial ekonomi <UMR Ada hubungan antara dukungan keluarga dengan pemilihan tempat persalinan di Puskesmas Tebing Tinggi dengan kategori sedang Ada hubungan 
antara sosial ekonomi dengan pemilihan tempat persalinan di Puskesmas Tebing Tinggi.

\section{UCAPAN TERIMAKASIH}

Peneliti Mengucapakan Terimakasih kepada seluruh pihak yang telah membantu dalam penelitian ini, khususnya pembimbing dan tempat penelitian.

\section{DAFTAR PUSTAKA}

Arief. M \& Sudikno. (2010) Determinan Pemilihan Persalinan Di Fasilitas Kesehatan (Analisis Data Riset Kesehatan Dasar Tahun 2010)

Badan Perencanaan Pembangunan Nasional (Bappenas). (2014). Rencana Pembangunan Jangka Menengah Nasional (RPJMN) 2015-2019. Jakarta. Kemenkes RI.(2017).Profil Kesehatan Indonesia. Jakarta

Dinas Kesehatan Kabupaten Empat Lawang.(2017).Profil Kesehatan Kabupaten Empat Lawang. Palembang: Dinas Kesehatan Kabupaten Empat Lawang

Dinas Kesehatan Kabupaten Empat Lawang.(2018). Profil Kesehatan Kabupaten Empat Lawang. Palembang: Dinas Kesehatan Kabupaten Empat Lawang

Dinas Kesehatan Provinsi Sumatera Selatan.(2017).Profil Kesehatan Provinsi Sumatera Selatan. Empat Lawang: Dinas Kesehatan Provinsi Sumatera Selatan

Dinas Kesehatan Provinsi Sumatera Selatan.(2018). Profil Kesehatan Kabupaten Empat Lawang.Empat Lawang: Dinas Kesehatan Provinsi Sumatera Selatan

Hidra, Majid, R. \& Rasma. (2017) Faktor Yang Berhubungan Dengan Pemilihan Tenaga Penolong Persalinan Di Wilayah Kerja Puskesmas Pasir Putih Kabupaten Muna Tahun 2016. Jimkesmas Jurnal Ilmiah Mahasiswa Kesehatan Masyarakat VOL. 2/NO. 6/ Mei 2017; ISSN 2502-731X,

Kemenkes RI. (2017). Profil Kesehatan Indoenesia. Jakarta

Kemenkes RI. (2018). Profil Kesehatan Indoenesia. Jakarta

Nurhidayanti, S. Margawati. A. \& Irene, M. (2018). Kepercayaan Masyarakat terhadap Penolong Persalinan di Wilayah Halmahera Utara. Jurnal Promosi Kesehatan Indonesia Vol 13 No.1 Januari 2018. Hal : 46 - 60. 
Nurjanah. S \& Marliyah, S. (2016). Hubungan Pengetahuan Dan Dukungan Keluarga Pada Ibu Hamil Trimester III Dengan Pemilihan Tempat Bersalin Di Kelurahan Sendangmulyo Kota Semarang. RAKERNAS AIPKEMA 2016 "Temu Ilmiah Hasil Penelitian Dan Pengabdian Masyarakat.Hal 324- 330

Okan C.A, \& Kaseje, D. (2015). The Pull and Push Factors Influencing Choice of Place and Delivery Attendant in the Urban Slums of Nyalenda, Kisumu East District, Kenya. Department of Community Health and Development Great Lakes University of Kisumu Kenya. Faculty of Tropical Institute of Community Health and Development Great Lakes University of Kisumu. International Journal of Humanities and Social Science. Vol. 5, No. 8(1), pp. 133-40.

Prihatin. S.G, Rahmawan. E.D, Wardhani. L.K Akbar. J, Ayunita. R, Nabila. F, Supriyadi. G, \& Wardani, I.B.K (2017). Analisis Faktor-Faktor yang Berhubungan dengan Pemilihan Tempat Persalinan Tahun 2016 (Studi di Wilayah Puskesmas Perawatan Suban Kabupaten Tanjung Jabung Barat). Jurnal Kesehatan Masyarakat Volume 5, Nomor 3, Juli 2017 Hal : 218-225

Putri, D. P.(2016). Faktor-Faktor Yang Berhubungan Dengan Pemilihan Tempat Persalinan Tahun 2015 (Studi Di Kecamatan Sarolangun Kabupaten Sarolangun Jambi). Jurnal Kesehatan Masyarakat (E-Journal) Volume 4, Nomor 2:56-67

Rumengan, D. S. S, Umboh, J. M. L, \& Kandou, G. D. (2015). Faktor-Faktor yang Berhubungan dengan Pemanfaatan Pelayanan Kesehatan Pada Peserta BPJS Kesehatan di Puskesmas Paniki Bawah Kecamatan Mapanget Kota Manado JIKMU, Suplemen Vol, 5. No, 1 Januari 2015 